\title{
SOLVING OPTIMAL ASSEMBLY LINE CONFIGURATION TASK BY MULTI- OBJECTIVE DECISION MAKING METHODS
}

\author{
Ján ČABALA, Ján JADLOVSKÝ \\ Department of Cybernetics and Artificial Intelligence, Faculty of Electrical Engineering and Informatics, \\ Technical University of Košice, Vysokoškolská 4, 04200 Košice, Slovak Republic, Tel.: +421 556024218 , \\ E-mail: jan.cabala@tuke.sk,jan.jadlovsky@tuke.sk
}

\begin{abstract}
This paper deals with looking for the optimal configuration of automated assembly line model placed within Department of Cybernetics and Artificial Intelligence (DCAI). In order to solve this problem, Stateflow model of each configuration was created to simulate the behaviour of particular assembly line configuration. Outputs from these models were used as inputs into the multiobjective decision making process. Multi-objective decision-making methods were subsequently used to find the optimal configuration of assembly line. Paper describes the whole process of solving this task, from building the models to choosing the best configuration. Specifically, the problem was resolved using the experts' evaluation method for evaluating the weights of every decision-making criterion, while the ELECTRE III, TOPSIS and AGREPREF methods were used for ordering the possible solutions from the most to the least suitable alternative. Obtained results were compared and final solution of this multi-objective decisionmaking problem is chosen.
\end{abstract}

Keywords: multi-objective decision making, assembly lines, experts' evaluation, ELECTRE, TOPSIS, AGREPREF

\section{INTRODUCTION}

Multi-objective decision making (MODM) is the type of decision-making, which is helpful for decision maker in choosing the best solution from wide portfolio of possible solutions. Decision maker has to choose the criteria (objectives), according to which possible solutions are compared. Another task for decision maker is to define the importance (weight) of every criterion. Consequently, evaluation of every possible solution according to every criterion has to be realised as the last step necessary for definition of the complex multi-objective decision making task.

MODM problem described in this paper deals with looking for optimal configuration of assembly line model placed in Department of Cybernetics and Artificial Intelligence (Fig. 1).

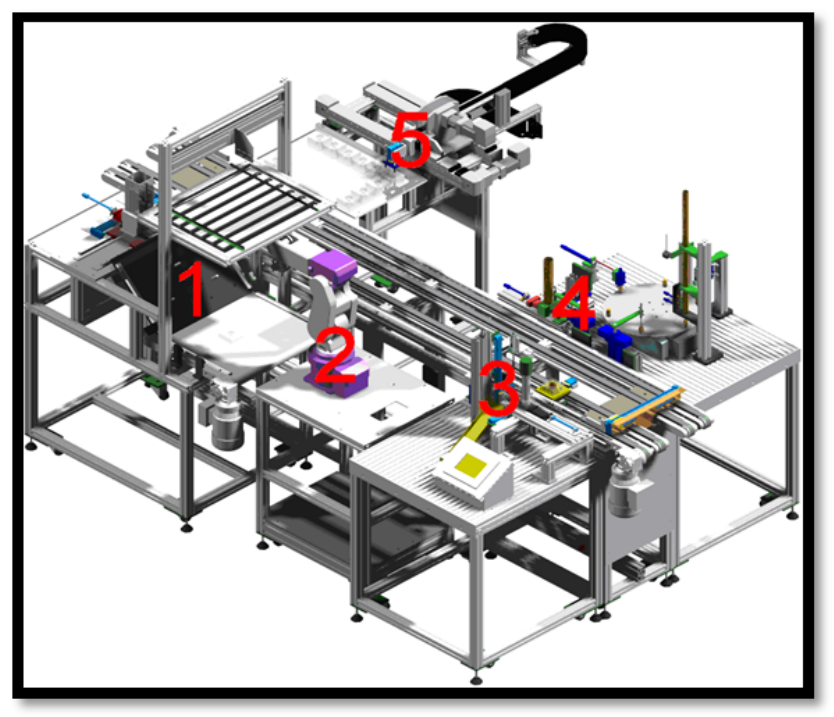

Fig. 1 Assembly line model
This model consists from five posts. Within the production process, there are many overloads slowing down the production process and thus reducing the efficiency of the assembly line. Goal of this research paper was to find optimal configuration of this assembly line from defined portfolio (only alternatives respecting the space limitations were considered). Five simulation models of five different configurations were constructed in MATLAB/Simulink in order to simulate the behaviour of every configuration and to reach their quantitative parameters. Outputs of these models (final production time, time in queue on particular post etc.) were used as inputs into the multi-objective decision making process

Within the MODM process, the experts' evaluation method was chosen for definition of criteria importance, while TOPSIS, ELECTRE III and AGREPREF methods were used for choosing the best assembly line configuration from defined portfolio.

Finding the optimal assembly line configuration is only one of the many application possibilities of MODM methods e.g. performance of clusters in Czech Republic was evaluated in [1] using methods AGREPREF, ELECTRE, PROMETHEE and MAPPAC. Solving environmental problems using these methods is also discussed in [2]. A review of MODM methods used for supplier evaluation and selection is the main theme in [3]. Usage of multiple-criteria decision making in assembly line field is presented in paper [4], where goal programming and fuzzy goal programming methods are used for balancing the two-sided assembly line.

\section{MULTI-OBJECTIVE DECISION-MAKING METHODS}

According to [5], process of multi-criteria decisionmaking is divided into five phases, namely:

1. Definition of a set of alternatives, from which the final solution is chosen. 
2. Definition of the criteria which are taken into account in the selection realized by decision maker.

3. Definition of importance (weight) of each of the criteria.

4. Evaluation for every alternative according to every criterion.

5. Choosing the best solution by methods of multicriteria decision-making.

In this chapter, methods for criteria choosing and evaluation of their importance are presented, as well as methods for solving multi-objective decision-making problems. Computational process of every method is presented, complemented by mathematical background of used methods.

\subsection{Methods for criteria choosing and evaluation}

This chapter sets out the method used for evaluation of importance of every criterion used in decision-making process.

There are many possibilities for evaluation of the criteria. Choosing the method depends on the number of experts involved in this process:

- One expert - Saaty's method

- Group of experts - paired comparison method, ranking method, scoring method, experts' evaluation method [6].

From this portfolio, experts' evaluation method was chosen due to its iterative process and the fact, that this method takes both evaluation of the criteria and relevance of particular expert's opinion into account. The importance (weight) of every criterion is subsequently used in the MODM process. The purpose of these methods is the enlargement of the weight's objectification, in other words, definition of criteria's weights, which would reflect the preferences of the decision maker in the best way.

The experts' evaluation method can be helpful in the selection of criteria important for decision-making process, as well as for their evaluation in terms of their relevance for the optimization or decision making process.

\subsubsection{Experts' evaluation method}

This method was chosen for evaluation of the importance of every criterion used in decision-making process. In the first phase, from a set of evaluation criteria, experts select the set of most important ones. The second stage is the assignment of weights to the criteria that have been selected in the previous step. Computational process of this method is described in details in [7].

Firstly, experts assign weights to each criterion signifying their importance for decision-making. Thus, the $k^{\text {th }}$ expert assign the number

$a_{k j}^{\prime}(j=1,2, \ldots, m ; k=1,2, \ldots, s)$

to the $j^{\text {th }}$ criterion, where $m$ is the number of criteria and the $s$ is number of experts. Subsequently, the values of these weights are standardized, so the sum of the ratings of each expert evaluation equals 1. Standardization is performed on the basis of the formula

$a_{k j}=\frac{a_{k j}^{\prime}}{\sum_{j=1}^{m} a_{k j}^{\prime}}, j=1,2, \ldots, m$

Values $a_{k j}$ are used for creation of the $\boldsymbol{T}$ matrix - an array that represents an initial evaluation of criteria importance defined by every expert.

In the calculation it is assumed that the credibility value of each expert $(h)$ is identical at the beginning equals 1 , what can be defined as

$h_{k(1)}=1$, for $k=1,2, \ldots, s$,
$\sum_{k=1}^{s} h_{k(1)}=s$.

Afterwards, an iterative process for the weights adjustments of individual criteria takes place. In the first step, mean of each column (evaluation of all experts for particular criterion) is calculated from $\boldsymbol{T}$ matrix (where $n$ is the number of iterations) according to equation

$a_{j(n)}^{\prime}=\frac{\sum_{k=1}^{s} a_{k j}}{s}, \quad j=1,2, \ldots, m$

The next step is standardization of the calculated mean values, for their sum being equal to one. This is defined as

$a_{j(n)}=\frac{a_{j(n)}^{\prime}}{\sum_{j=1}^{m} a_{j(n)}^{\prime}}, j=1,2, \ldots, m$.

For further procedure it is necessary to calculate the difference between standardized means and the value of each expert's evaluation (matrix $\boldsymbol{T}$ ). These offsets are subsequently used to calculate changes in the coefficient of credibility for each expert. Uncertainty of $k^{\text {th }}$ expert in $n^{\text {th }}$ iteration $\left(d_{k(n)}\right)$ is determined by the relationship

$d_{k(n)}=\sum_{j=1}^{m}\left|a_{j(n)}-a_{k j}\right|$,

for $k=1,2, \ldots, s$.

Subsequently, the new credibility rate for $\mathrm{k}^{\text {th }}$ expert $\left(h_{k(n+1)}\right)$ is determined as

$h_{k(n+1)}=\frac{p}{d_{k(n)}}, k=1,2, \ldots, s ; p=\frac{s}{\sum_{k=1}^{s} \frac{1}{d_{k(n)}}}$

Elements $h_{k(n+1)}$ are put on the great diagonal of the matrix $\boldsymbol{H}_{n+1}$ (outside the main diagonal elements are equal to 0 ). This matrix will be used in calculating the new matrix for criteria evaluation - $\boldsymbol{T}_{n+1}$, where

$\boldsymbol{T}_{n+1}=\boldsymbol{H}_{n+1} \cdot \boldsymbol{T}_{n}$

Whole iterative process is repeated until the sum of deviations between calculated credibility coefficients in two successive iterations is less than a predetermined value $\varepsilon$, so until the condition (9) is fulfilled. 
$\sum_{j=1}^{m}\left|a_{j n}-a_{j n-1}\right| \leq \varepsilon$

\subsection{Methods for multi-objective decision making}

Multi-objective decision-making (MODM) methods are methods used for automation of decision-making process. This process is more objective than classic human decision-making, because it chooses the best solution from the feasible solutions for particular problem.

These methods are used in the design phase of optimizing the operation of production lines, where the selection of most suitable layout of assembly line's components is realized. During the process of MODM, many possible ways of assembly line configuration are considered, and the most suitable solution is then chosen by MODM methods.

Multiple Objective Decision Making methods can be divided into:

- axiomatic methods,

- direct methods,

- compromised methods,

- threshold methods.

In this paper, threshold methods (ELECTRE III and AGREPREF), and one of direct methods (TOPSIS) will be described in details, used for solving the MODM problem of assembly line model configuration, their results will be compared and the conclusion from this comparison will be stated.

Comparison of these and many other MODM methods with their advantages and disadvantages can be found in [8].

\subsubsection{ELECTRE III method}

ELECTRE III method is the part of ELECTRE methods, belonging to the group of threshold MODM methods. For using this method, 3 thresholds have to be defined for every criterion:

- $\quad$ preference threshold $p_{j}$,

- $\quad$ indifference threshold $q_{j}$,

- $\quad$ veto threshold $v_{j}$.

This method tries to improve the imperfections of the previous ELECTRE methods (especially methods ELECTRE I and II). Closer description of ELECTRE group can be found in [9].

Especially in the past decade, the method was used to solve a wide range of decision-making problems in various fields of real life. The main change from the older method of ELECTRE is the usage of pseudo-criteria rather than actual ones.

In [9], binary relationship in ELECTRE III is considered as a fuzzy relation, since each binary relationship $a R b$ requires the definition of the credibility index, which defines the strength of the claim " $a$ outranks $b(a R b)$. Let's define the index $\rho(a R b)$. This index is defined using the two other indices of the method:
1. concordance index $\left(c_{j}\right)$ :

Values of concordance indices are written into concordance matrix $\boldsymbol{C}(a, b)$.

Let's define:

- $k_{j}$ as the weight of the $\mathrm{j}$-th criterion,

- $g_{j}$ as the value of the $\mathrm{j}$-th criterion,

- $c_{j}(a, b)$ as the concordance index,

- $r$ as the number of the criteria.

Then:

$C(a, b)=\frac{1}{k} \sum_{j=1}^{r} k_{j} c_{j}(a, b)$, where $k=\sum_{j=1}^{r} k_{j}$,

where:

$c_{j}(a, b)=1$, if $g_{j}(a)+q_{j} \geq g_{j}(b)$,

$c_{j}(a, b)=0$, if $g_{j}(a)+p_{j} \leq g_{j}(b)$,

$c_{j}(a, b)=\frac{p_{j}+g_{j}(a)-g_{j}(b)}{p_{j}+q_{j}}$,

$j=1, \ldots, r$.

\section{2. discordance index $\left(d_{j}\right)$ for every criterion:}

This index tells how much the criterion $g_{j}$ is discordant to an assertion $a R b$. It reaches a maximum value when the criterion $g_{j}$ is prohibiting the assertion and is minimized when the criterion is not inconsistent with this assertion. Index is evaluated in the following way:

$d_{j}(a, b)=1, \quad$ if $g_{j}(b)>g_{j}(a)+v_{j}\left(g_{j}(a)\right)$

$d_{j}(a, b)=0, \quad$ if $g_{j}(b) \leq g_{j}(a)+p_{j}\left(g_{j}(a)\right)$

$d_{j}(a, b)=\frac{g_{j}(b)-g_{j}(a)-p_{j}\left(g_{j}(a)\right)}{v_{j}\left(g_{j}(a)\right)-p_{j}\left(g_{j}(a)\right)}$,

Once these indices are defined, process continues with calculating the credibility indices for assertion $a R b$ :

1. if $d_{j}(a, b) \leq C(a, b)$ for $\forall j$

(if there is no discordant criterion):

$\rho(a R b)=C(a, b)$,

2. in other cases:

$\rho(a R b)=C(a, b) * \prod_{j \in J(a, b)} \frac{1-d_{j}(a, b)}{1-C(a, b)}$.

In (13), $J(a, b)$ is a set of criteria, for which the $d_{j}(a, b)>C(a, b)$. The results are written to the credibility matrix $S(a, b)$.

Set (13) of formulas says that if the concordance index is greater than discordance index for every criterion, the credibility index equals the value of concordance index. Otherwise, credibility index is calculated as the modification of concordance index on the basis of the second part of the formula (13).

The next step is to use the results of the method ELECTRE III for the ordering of the alternatives. Final order $\mathrm{Z}$ is established by merging two partial orderings $\mathrm{Z} 1$ and Z2 (descending and ascending ordering).

The first step in ordering the alternatives is definition of the constant $\lambda$ ( $\boldsymbol{A}$ is the whole set of alternatives):

$\lambda=\max _{a, b \in A} S(a, b)$. 
It is also necessary to ensure that the results with high credibility level will be taken into account. Therefore, credibility border $s(\lambda)$ is defined. Subsequently, the matrix $\mathbf{T}$ is defined, filled with values:

$T(a, b)=1$, if $S(a, b)>\lambda-s(\lambda)$

$T(a, b)=0$, in other cases.

The value of the $s(\lambda)$ is relatively low generally, to ensure a high level of credibility.

The next step is to define the classification of each possible solution $-Q(a)$, defined as the difference between the number of alternatives, to which the alternative $a$ is outranking, from the alternatives, which outranks the alternatives $a$. In terms of $\mathbf{T}$ matrix, it is the difference between the sum of particular row and sum of particular column of $\mathbf{T}$ matrix. The set of alternatives with the largest value of $\mathrm{Q}$ is selected in the first distillation D1. If D1 contains only one alternative, the process is repeated with A / D1. If it contains more options, the process is repeated within the D1. The whole procedure runs until emptying of $\mathrm{A}$.

Process of creating the ascending order is analogical, but within each distillation, the solution with minimal Q value is chosen.

\subsubsection{TOPSIS method}

TOPSIS method name was established as an abbreviation of the English short for Technique for Order Preference by Similarity to Ideal Solution. As the acronym suggests, this method is based on sorting the possible solutions according to their distance from the ideal solution. Computational process of TOPSIS method is described in [7].

The first step of TOPSIS method is to build a matrix $\boldsymbol{X}$, which elements $x_{i j}$ are calculated by multiplying the evaluation of every possible solution (matrix $\boldsymbol{E}$ ) by every criterion, and the weight of particular criterion:

$x_{i j}=E_{i j} * w_{j}$.

The number of criteria is defined as $m$. Combining maximum values from $\boldsymbol{X}$ for every criterion, vector of ideal object $\left(s^{+}\right)$is created. On the contrary, vector of basal object $\left(s^{-}\right)$is created by choosing minimum values of the particular criteria:

$s_{j}^{+}=\max _{i}\left(x_{i j}\right)$

$s_{j}^{-}=\min _{i}\left(x_{i j}\right)$, for $j=1,2, \ldots, m$.

The next step is to quantify the Euclidean distance of each solution from the ideal $\left(D_{i}^{+}\right)$and from basal $\left(D_{i}^{-}\right)$ object as:

$D_{i}^{+}=\sqrt{\sum_{j=1}^{m}\left(w_{j} x_{i j}-s_{j}^{+}\right)^{2},}$
$D_{i}^{-}=\sqrt{\sum_{j=1}^{m}\left(w_{j} x_{i j}-s_{j}^{-}\right)^{2} .}$
The decisive factor determining the final order of the alternatives is the relative distance of each alternative from the ideal object $(\boldsymbol{C})$ defined by the formula

$C_{i}=\frac{D_{i}^{-}}{D_{i}^{+}+D_{i}^{-}}$.

$C_{i}$ values are placed within the interval $<0,1>$. Possible solutions are sorted in the descending order, so the best alternative has its $C$ value closest to 1 .

Usage of TOPSIS method in solving supplier selection MODM problem is the main part of the [10].

\subsubsection{AGREPREF method}

According to [11], AGREPREF method is based on an aggregation of partial preferences of particular solutions. Method uses two thresholds during ordering process indifference threshold and preference threshold. Indifference threshold $\alpha$ is defining the minimum sum of criteria weights, according to which two solutions $(x, y)$ are indifferent, to consider whole $x \quad R \quad y$ relation as indifferent. Preference threshold $\pi$ represents the desired difference between the sum of the criteria weights, according to which the solution $x$ is outranking solution $y$, and the sum of the weights according to which the solution $y$ outranks solution $x$. Values of both thresholds are within the range $<0,1>$.

In the ELECTRE methods, values of weights are integers. On the other hand, in the method AGREPREF, for each criterion is valid that the weight $w_{i} \geq 0$ and also $\sum_{\mathrm{i}=1}^{\mathrm{m}} \mathrm{w}_{\mathrm{i}}=1$.

For each pair of alternatives $x$ and $y$ are calculated the amounts of weights of individual criteria for all situations that may arise:

1. $x$ outranks $y$

$S_{x y}=\sum w_{i}, \quad$ where $x_{i}>y_{i}$

2. $y$ outranks $x$

$S_{y x}=\sum w_{i}, \quad$ where $x_{i}<y_{i}$

3. $x$ and $y$ are indifferent

$S_{x \sim y}=\sum w_{i}$, where $x_{i}=y_{i}$

Then, three binary relations are defined:

$x I(\alpha) y \leftrightarrow S_{x y}>\alpha$,

$x P(\alpha, \pi) y \leftrightarrow S_{x y}-S_{y x}>\pi$,

$y P(\alpha, \pi) x \leftrightarrow S_{y x}-S_{x y}>\pi$,

Based on these relationships, incidence matrix $\boldsymbol{A}$ is created containing elements $a_{j k}$ with values:

$a_{j k}=1$, if $\left(x^{j}, x^{k}\right) \in R(\alpha, \pi)$

$a_{j k}=0$, if $\left(x^{j}, x^{k}\right) \notin R(\alpha, \pi)$

Subsequently, two evaluating characteristics are calculated. The first, which indicates the number of alternatives, before which the alternative $x$ is preferred $\left(d_{k+}\right)$ and the other, which indicates the number of alternatives, which outranks the alternative $x\left(d_{k-}\right)$ : 


$$
\begin{aligned}
& d_{k+}=\sum_{j=1}^{n} p_{k j}, \\
& d_{k-}=\sum_{j=1}^{n} p_{j k} .
\end{aligned}
$$

The final evaluation is counted as the difference of these two characteristics.

Application possibility of AGREPREF method in increasing reliability of system components can be found in [12].

\section{SOLVING OPTIMAL ASSEMBLY LINE CONFIGURATION TASK BY MODM}

In this part of paper, optimal assembly line configuration task is solved using methods described in previous chapter. Assembly line model installed in laboratory within DCAI consists of which are arranged in a series. The schema of the assembly line is shown in Fig. 1.

Goal of this task is to find out, if it would be worth considering parallelization of critical posts of this assembly line, where overloads are slowing the fluency of the production process. For this purpose, simulation models of assembly lines configuration were constructed in MATLAB/Simulink environment for every considered configuration. Outputs from these models were used to calculate the inputs for the MODM process. Closer description of one of the Stateflow models can be found in [13]. Simulink model containing Stateflow block with configuration of one of the assembly line variants is displayed in Fig. 2.

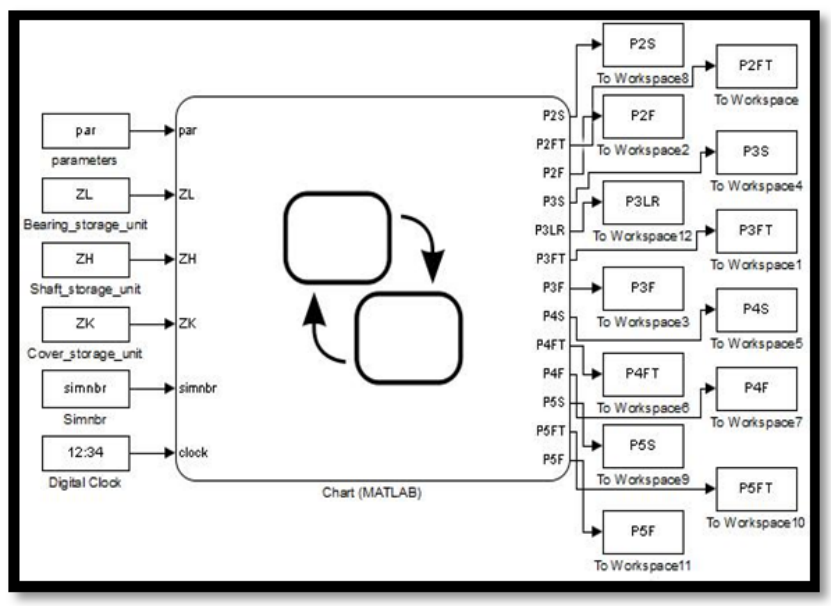

Fig. 2 Simulink model of V1 assembly line configuration

Within MODM process, 5 variants of the assembly line layout were taken into account:

- V1: current state (one station per post),

- V2: add stand to post 3,

- V3: add stand to post 4,

- V4: add stand to post 3 and 4,

- V5: add stand to posts 3, 4 and 5.
All variants of possible assembly line configuration are displayed in Fig. 3.

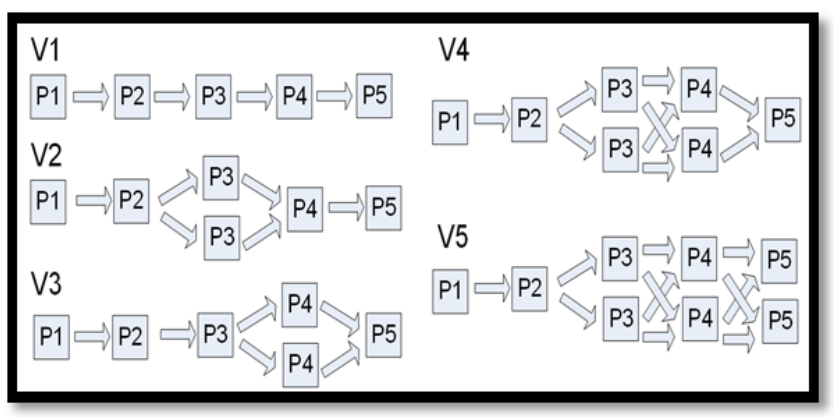

Fig. 3 Possible variants of assembly line configuration

Admission cost for the introduction of new workplace on post 3 is $€ 2,000$, the cost of adding workplace on post 4 is $€ 11,000$ and additional post 5 costs $€ 6,000$. Each added workplace represents an additional effect on the environment.

5 members of our research group have dealt on 4 criteria that will be taken into account while solving this problem:

- $\mathrm{C} 1$ : increase of the company's profit,

- $\mathrm{C} 2$ : minimizing overloads of the production line,

- C3: the impact on the environment,

- C4: the size of initial investment.

Every of these members had to define the importance of the individual criteria selected for decision-making. The results of this evaluation are in Table 1:

Table 1 Evaluation of criteria importance

\begin{tabular}{|c|c|c|c|c|}
\hline & C1 & C2 & C3 & C4 \\
\hline E1 & 0.7 & 0.1 & 0 & 0.2 \\
\hline E2 & 0.8 & 0.1 & 0.05 & 0.05 \\
\hline E3 & 0.5 & 0.1 & 0.3 & 0.1 \\
\hline E4 & 0.6 & 0.05 & 0.1 & 0.25 \\
\hline E5 & 0.5 & 0.2 & 0.2 & 0.1 \\
\hline
\end{tabular}

Subsequently, evaluation of all alternatives according to every criterion was created on the basis of the simulation results (10 simulations producing 100 products for every variant) and prices of additional components. Results of the evaluation are in Table 2.

Table 2 Data inputs

\begin{tabular}{|c|c|c|c|c|}
\hline & $\begin{array}{c}\text { Average } \\
\text { production } \\
\text { time (s) }\end{array}$ & $\begin{array}{c}\text { Average } \\
\text { time in } \\
\text { queue }(\mathrm{s})\end{array}$ & $\begin{array}{c}\text { Environ- } \\
\text { mental } \\
\text { impact }\end{array}$ & $\begin{array}{c}\text { Sum of } \\
\text { additional } \\
\text { costs }(€)\end{array}$ \\
\hline V1 & 1994.35 & 417.33 & 0 & 0 \\
\hline V2 & 1869.35 & 373.13 & 1 & 2000 \\
\hline V3 & 1897.57 & 394.89 & 2 & 11000 \\
\hline V4 & 1723.27 & 294.53 & 3 & 13000 \\
\hline V5 & 1153.58 & 15.08 & 4 & 19000 \\
\hline
\end{tabular}


0 - 100 scale for evaluating the suitability of all variants according to every criterion was established (0minimum, 100- maximum).

Results of this evaluation can be seen in Table 3:

Table 3 Evaluation of every possible solution

\begin{tabular}{|c|c|c|c|c|}
\hline & C1 & C2 & C3 & C4 \\
\hline V1 & 0 & 0 & 100 & 100 \\
\hline V2 & 15 & 11 & 75 & 89 \\
\hline V3 & 12 & 6 & 50 & 42 \\
\hline V4 & 32 & 31 & 25 & 32 \\
\hline V5 & 100 & 100 & 0 & 0 \\
\hline
\end{tabular}

For definition of the optimal assembly line configuration, methods described in chapter 2 were used, results were compared and then the best alternative was chosen.

Whole decision-making process was realized by the application created in MATLAB simulating system. This application was designed to solve MODM problems from various fields, and is specialized for solving MODM problems via methods ELECTRE I - IV, TOPSIS and AGREPREF as well as for solving multi-criteria optimization tasks. Detail description of this application with focus on its multi-objective optimization part is written in [14]. In [15], also the MODM part of the application is described.

\section{RESULTS FROM MULTI-OBJECTIVE DECISION MAKING PROCESS}

In this chapter, methodology defined in previous chapters is applied on solving MODM problem described in Chapter 3. Results from MODM process using 3 MODM methods are shown using tables and graphs.

\subsection{Definition of criteria importance}

To calculate the final weights of criteria, the experts' evaluation method was used. Final weights of particular criteria were calculated from criteria evaluation in Table 1. Iterative process was repeated 31 times in order to define the final weights with sufficient precision. Iterative process was realized using MATLAB scripts. Final weights for TOPSIS and AGREPREF method are displayed in Table 4:

Table 4 Final weights for TOPSIS and AGREPREF methods

\begin{tabular}{|l|c|c|c|c|}
\hline Criterion & C1 & C2 & C3 & C4 \\
\hline Weight & 0.6922 & 0.082 & 0.0547 & 0.1711 \\
\hline
\end{tabular}

One of the requirements for ELECTRE methods is that the criteria weights must be defined as positive integers. For this reason, final weights for ELECTRE method were calculated from values in Table 4 , which were multiplied by 100 and rounded. Final weights for ELECTRE method are shown in Table 5.
Table 5 Final weights for ELECTRE III method

\begin{tabular}{|l|c|c|c|c|}
\hline Criterion & C1 & C2 & C3 & C4 \\
\hline Weight & 69 & 8 & 6 & 17 \\
\hline
\end{tabular}

\subsection{Choosing the best alternative of assembly line configuration}

For solving MODM problem of optimal assembly line configuration, three MODM threshold methods were used: ELECTRE III, TOPSIS and AGREPREF.

\subsubsection{Solution using ELECTRE III method}

In ELECTRE III method, final order of the alternatives is created from two partial orderings: top-bottom and bottom-top ordering. Final order is defined as a mean of the alternative place in both orderings. In the Table 6 , the evaluation of every alternative in both partial orderings is shown (lower evaluation $=$ better alternative):

Table 6 Partial ordering in ELECTRE III method

\begin{tabular}{|c|c|c|}
\hline & Top-bottom order & Bottom-top order \\
\hline V1 & 2 & 1 \\
\hline V2 & 3 & 1 \\
\hline V3 & 3 & 3 \\
\hline V4 & 2 & 2 \\
\hline V5 & 1 & 1 \\
\hline
\end{tabular}

Final ordering of ELECTRE III method is displayed in graph in Fig. 4:

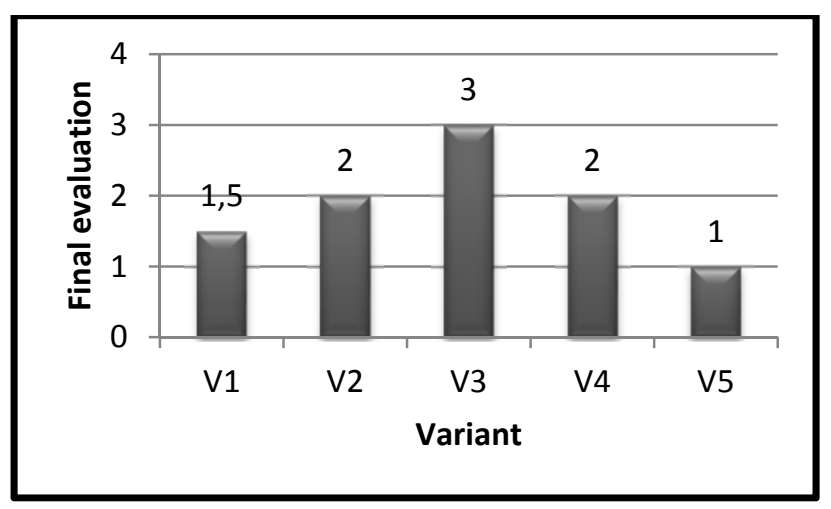

Fig. 4 Final order - ELECTRE III method

\subsubsection{Solution using TOPSIS method}

In TOPSIS method, order of the alternatives is based on their relative distance from ideal and basal object. In the final calculation, the distance from basal object is divided by sum of distances from ideal and basal objects (formula 19). Thus, better alternatives obtained higher values of this coefficient. Results of the TOPSIS method are shown in Fig. 5: 


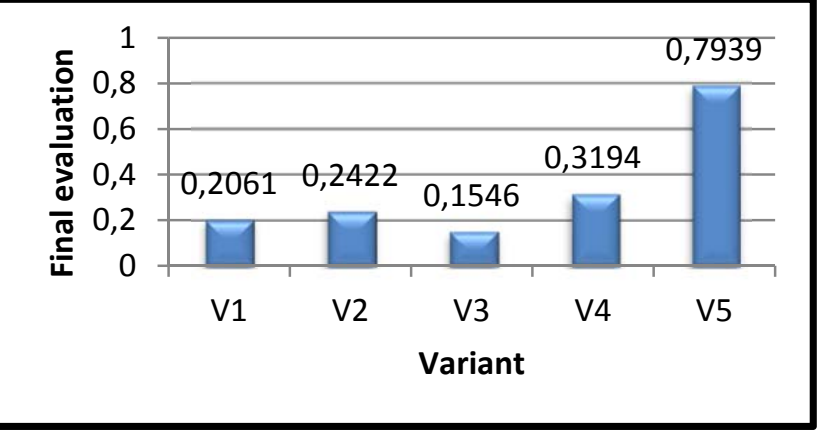

Fig. 5 Final order - TOPSIS method

\subsubsection{Solution using AGREPREF method}

Final evaluation of every alternative for the optimal assembly line configuration realized by AGREPREF method is counted as the difference between the number of alternatives outranked by particular solution and number of alternatives outranking this solution (formulas 25). Final evaluation of the alternatives is in Fig. 6 (higher evaluation $=$ better alternative):

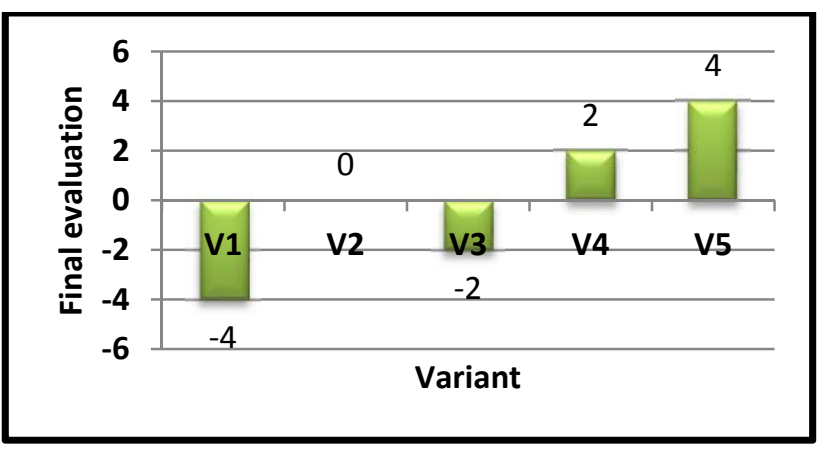

Fig. 6 Final order - AGREPREF method

\subsubsection{Summarization}

For final summarization, Table 7 with descending order (from best variant to the worst one) of variants for every MODM method is displayed:

Table 7 Comparison of MODM methods

\begin{tabular}{|l|c|c|c|}
\hline & ELECTRE III & TOPSIS & AGREPREF \\
\hline $1^{\text {st }}$ & V5 & V5 & V5 \\
\hline $2^{\text {nd }}$ & V1 & V4 & V4 \\
\hline $3^{\text {rd }}$ & V2/V4 & V2 & V2 \\
\hline $4^{\text {th }}$ & V2/V4 & V1 & V3 \\
\hline $5^{\text {th }}$ & V3 & V3 & V1 \\
\hline
\end{tabular}

\section{CONCLUSIONS}

From the obtained results it is clear that the best alternative for the configuration of the assembly line is variant V5 with 2 parallel workstations on posts 3, 4 and 5. Although the highest initial investment is inevitable, it is the most time-saving and profit-maximizing alternative. This fact corresponds with the fact, that the most important criterion in MODM process was the $\mathrm{C} 1$ : increase of the company's profit.

In the results depicted in Table 7, small differences in the final order of possible solutions can be discovered. These differences are raised due to different mathematical background and algorithms of the MODM methods (in ELECTRE III and AGREPREF, final order of alternatives can be also affected by the threshold values). This is why more than one MODM method was used in resolving this problem, and only after the comparison of results calculated by all methods, the best alternative was chosen. If the results from various methods were more conflicting, approach for dealing with the results would have to be chosen. Emphasis of our future research will be given on these situations.

Process of MODM illustrated in this paper can be used in solving more complex issues dealing with configuration or design of assembly line, as well as for solving problems from other areas.

\section{ACKNOWLEDGMENTS}

This work has been supported by the Research and Development Operational Program for project: University Science Park Technicom for innovative applications with knowledge technology support $-2^{\text {nd }}$ phase, ITMS code 313011D232 (40\%), and grant TUKE FEI-2015-33: Research Laboratory of Nonlinear Underactuated Systems $(30 \%)$. This publication also arose thanks to grant KEGA - 001TUKE-4/2015 (10\%) and to the support of the Operational Programme Research and development for the project "Centre of Information and Communication Technologies for Knowledge Systems" (ITMS code 26220120020), co-financed by the European Regional Development Fund (20\%).

\section{REFERENCES}

[1] MAREŠOVÁ, P. - JAŠÍKOVÁ, V. - TROUSIL, M.: Method for evaluating the performance of clusters in the Czech Republic. In: Proceedings of the 2nd International Conference on Urban sustainability, cultural sustainability, green development, green structures and clean cars, Prague, Czech Republic. 2011, pp. 30-35.

[2] SALMINEN, P. - HOKKANEN, J. - LAHDELMA, R.: Comparing multi-criteria methods in the context of environmental problems. European Journal of Operational Research, 1998, 104.3: 485-496.

[3] HO, W. - XU, X. - DEY, P. K.: Multi-criteria decision making approaches for supplier evaluation and selection: A literature review. European Journal of Operational Research, 2010, 202.1: 16-24.

[4] ÖZCAN, U. - TOKLU,B.: Multiple-criteria decision-making in two-sided assembly line balancing: A goal programming and a fuzzy goal programming models. Computers \& Operations Research, 2009, 36.6: 1955-1965. 
[5] CATERINO, N. et al.: A comparative analysis of decision making methods for the seismic retrofit of rc buildings, In: The 14th World Conference on Earthquake Engineering, Beijing, China, 2008, pp. 12-17.

[6] FANDEL, P.: Možnosti použitia DEA vo viackriteriálnom rozhodovaní $\mathrm{s}$ intervalovo zadanými váhami kritérí (Use of DEA in multiple criteria decision making with interval weights of criteria), Acta Oeconomica, 2006, 9.2: 32-36.

[7] OCELÍKOVÁ, E.: Multikriteriálne rozhodovanie (Multicriterial decision-making), 1st. ed. Košice: FEI TU, 2011, 119 pages, ISBN 978-80-553-0653-7.

[8] VELASQUEZ, M. - HESTER, P. T.: An analysis of multi-criteria decision making methods, International Journal of Operations Research, 2013, 10.2: 56-66.

[9] FIGUEIRA, J. - ROY, B. - MOUSSEAU, V.: Electre methods, Available on internet: $<$ http://11.lamsade.dauphine.fr/dea103/ens/bouyssou/ Outranking_Mousseau.pdf

[10] BORAN, F. E. et al.: A multi-criteria intuitionistic fuzzy group decision making for supplier selection with TOPSIS method, Expert Systems with Applications, 2009, 36.8: 11363-11368.

[11] GAŠPAR, V. et al.: Rozhodovanie a zložitost' (Decision-making and complexity), 1st. ed. Košice: FEI TU, 2016, 215 pages, ISBN 978-80-553-2523-1.

[12] JURICA, L. et al.: Aplication of New Method of Multi-Criteria Analysis. Advances in Electrical and Electronic Engineering, 2006, 5.1-2: 82.

[13] ČABALA, J. - JADLOVSKÝ, J.: Application of Stateflow Diagrams in Production Line Modeling.
In: SAMI 2016: IEEE 14th International Symposium on Applied Machine Intelligence and Informatics, January 21-23, 2016, Herl'any, Slovakia. Danvers: IEEE, 2016, pp. 125-130.

[14] ČABALA, J. - JADLOVSKÝ, J.: Optimization Toolbox Usage in Solving Vector Optimization Tasks, Technical Computing Bratislava 2014 Proceeding, Germany: Lap Lambert Academic Publishing, 2015, pp. 45-64.

[15] ČABALA, J.: Definition of methodology for multiobjective assembly line optimization process, 2016, dissertation prospectus (in Slovak).

Received January 9, 2017, accepted June 1, 2017

\section{BIOGRAPHIES}

Ján Čabala was born on June $7^{\text {th }}$, 1991. In 2014 he graduated (Ing.) with distinction at the department of Cybernetics and Artificial Intelligence of the Faculty of Electrical Engineering and Informatics at Technical University of Košice. He is now in the $3^{\text {rd }}$ year of his $\mathrm{PhD}$ studies in the field of multi-criteria assembly line optimization. This topic is also the main field of his research work. In addition, he is also focused on database systems, OLAP operations and data analysis.

Ján Jadlovský was born on June $13^{\text {th }}$, 1960. He graduated in the field of Technical cybernetics at Electrotechnical faculty of Technical University of Košice with focus on robotics. In this workplace he vindicated his dissertation work in 1990 and in 1994 he was habilitated for associate professor with his habilitation thesis dealing with distributed control systems. He is focused on this topic also in his research and teaching activities on Department of Cybernetics and Artificial Intelligence at Faculty of Electrical Engineering and Informatics of Technical University of Košice. 